\title{
Treatment of nonsyndromic dentigerous cysts in primary dentition
}

\author{
Mehmet Cemal Akay \\ Erdem Kaya \\ Mert Zeytinoğlu \\ Faculty of Dentistry, Department \\ of Oral and Maxillofacial Surgery, \\ Ege University, Bornova, \\ Izmir, Turkey
}

This article was published in the following Dove Press journal:

Clinical, Cosmetic and Investigational Dentistry

24 February 20II

Number of times this article has been viewed
Objective: Dentigerous cysts are benign odontogenic cysts that are associated with the crowns of permanent teeth. They usually occur singly and are located in the mandible. Nonsyndromic bilateral dentigerous cysts (NSBDC) are rarely seen during childhood. The aim of this study was to determine the long-term effects of the marsupialization technique in growing children with NSBDC.

Study design: Seven patients with NSBDC (4 female, 3 male) ranging in age from 7 to 9 years (mean 8.35 years) were involved in the study. All the individuals were treated by marsupialization. Space-maintaining appliances were applied during permanent teeth eruption. Intraoral photographs, and panoramic and periapical films were taken before surgery and during healing.

Results: The NSBDC were successfully treated by the marsupialization technique and rapid healing period was observed in the growing patients, without any loss of permanent teeth. No recurrence was seen in the long-term follow-up period (3-10 years).

Conclusion: Our clinical and radiological results revealed that using the marsupialization technique in children with NSBDC provided safe healing of permanent teeth around the dentigerous cysts in a short period. However, treatment planning and regular clinical follow-ups are necessary to ensure clinical success.

Keywords: nonsyndromic bilateral dentigerous cysts, primary dentition, marsupialization

\section{Introduction}

Dentigerous cysts are commonly seen in dental practice. These cysts are the second most common odontogenic cysts after radicular cysts. They originate from reduced enamel epithelium after the crown of the tooth has begun to form. The cysts are most prevalent in third molar region and are therefore a common cause of a radiolucency associated with the crown of an impacted third molar. ${ }^{1}$ Patients with dentigerous cysts have no painful symptoms unless there is acute inflammatory exacerbation, thus explaining the fact that these lesions are often detected only during routine radiographic examination. But large cystic lesions can expand the cortical bone to such an extent that they cause displacement of teeth and root resorption in the adjacent teeth. ${ }^{2}$

Most dentigerous cysts are solitary. Bilateral and multiple cysts have been reported in patients with syndromes such as basal cell nevus syndrome, mucopolysaccharidosis and cleidocranial dysplasia.,

Very few case reports have reported the bilateral occurrence of dentigerous cysts associated with primary first molars or premolars in childhood. As noted in Table 1, only a few cases of nonsyndromic bilateral dentigerous cysts (NSBDC) have been reported in the literature. The incidence of the cysts is not completely known. ${ }^{5-13}$
Correspondence: Mehmet Cemal Akay Department of Oral and Maxillofacial Surgery, Ege University, Bornova 35100, Izmir, Turkey

Tel +90-232-388I 108 (Bus);

+90-232-3758070 (Home)

$\mathrm{Fax}+90-232-3398289$

Email cemalakay@yahoo.com 
Table I Reported cases of nonsyndromic bilateral dentigerous cysts

\begin{tabular}{|c|c|c|c|c|}
\hline Reference & Sex & Age (years) & Location & Treatment \\
\hline 5 & M & 14 & Md second molar and Mx. third molar & Enucleation \\
\hline 6 & $\mathrm{~F}$ & 15 & Md third molars and second premolar & Enucleation \\
\hline II & M & 6 & Mx canines & Enucleation \\
\hline 12 & M & 39 & Md third molars & No treatment \\
\hline 9 & M & 8 & Md first molars & Enucleation \\
\hline 4 & M & 42 & Md third molars & Enucleation \\
\hline 1 & $\mathrm{~F}$ & 3 & Md central incisors and first molars & Enucleation \\
\hline 14 & M & 38 & Md third molars & Enucleation \\
\hline 17 & M & 5 & Md first molars & Enucleation \\
\hline 18 & M & 15 & Md first molars & Enucleation \\
\hline 27 & M & 15 & Md second premolar and second molar & Enucleation \\
\hline 15 & $\mathrm{~F}$ & 15 & Md third molars & Enucleation \\
\hline 19 & $\mathrm{~F}$ & 7 & Md first molars & Enucleation \\
\hline 10 & $\mathrm{~F}$ & 57 & Md third molars & Enucleation \\
\hline 16 & M & 38 & Md third molars & Enucleation \\
\hline 20 & M & 9 & Md first molars & Enucleation \\
\hline 21 & $\mathrm{~F}$ & 52 & Mx third molars & Enucleation \\
\hline 13 & $\mathrm{~F}$ & 19 & Md third molars & Enucleation \\
\hline 28 & M & 51 & Md third molars & Marsupialization + Enucleation \\
\hline
\end{tabular}

Abbreviations: $M$, male; F, female; Md, mandibular; Mx, maxillary.

Treatment of choice in children with NSBDC is very important because of the growing permanent teeth buds around dentigerous cysts.

In this study, 7 growing patients with NSBDC treated by marsupialization are described and discussed in relation to other reported cases.

\section{Patients and methods}

From January 2000 until November 2007, 7 patients (4 female and 3 male) with NSBDC were included in this study. All patients were operated on at Ege University, Faculty of Dentistry, Department of Oral and Maxillofacial Surgery, Turkey. Patients with congenital syndromes and systemic diseases were excluded. The ages ranged from 7 to 9 years (mean 8.35 years). The patients' clinical data are shown in Table 2.

\section{Preoperative evaluation}

The patients were evaluated by a comprehensive clinical and radiologic examination. Intraoral photographs, and panoramic and periapical films were taken before surgery and during healing. The treatment process was explained to parents of patients before surgery, including the marsupialization, the application of the space-maintaining appliance, and the time needed for healing. All parents signed an informed consent.

\section{Surgical technique}

All patients were operated on under local anesthesia. The NSBDC were treated by the marsupialization technique (Table 2). Primary teeth around the cysts were extracted and the part of the cystic wall next to the extracted teeth was removed for decompression of the lesions. The stitches were removed after 7 days, and a removable space-maintaining appliance was installed, which was fabricated on the basis of an impression obtained 7 days after surgery. Spacemaintaining appliances were applied during permanent teeth eruption (Figures 1-3).

The removed surgical specimens were fixed in $10 \%$ buffered formalin solution and submitted for histologic examination.

Table 2 Clinical data of cases with nonsyndromic bilateral dentigerous cysts

\begin{tabular}{lllll}
\hline Patients & Sex & Age (years) & Location & Treatment \\
\hline I & F & 7 & Md second premolars & Marsupialization \\
2 & F & 8 & Md second premolars & Marsupialization \\
3 & M & 7 & Md second premolars & Marsupialization \\
4 & M & 8 & Mx and Md second premolars & Marsupialization \\
5 & F & 9 & Mx canines & Marsupialization \\
6 & F & 8 & Mx canines and premolars & Marsupialization \\
7 & M & 9 & Md second premolars & Marsupialization \\
\hline
\end{tabular}

Abbreviations: M, male; F, female; Md, mandibular; Mx, maxillary. 

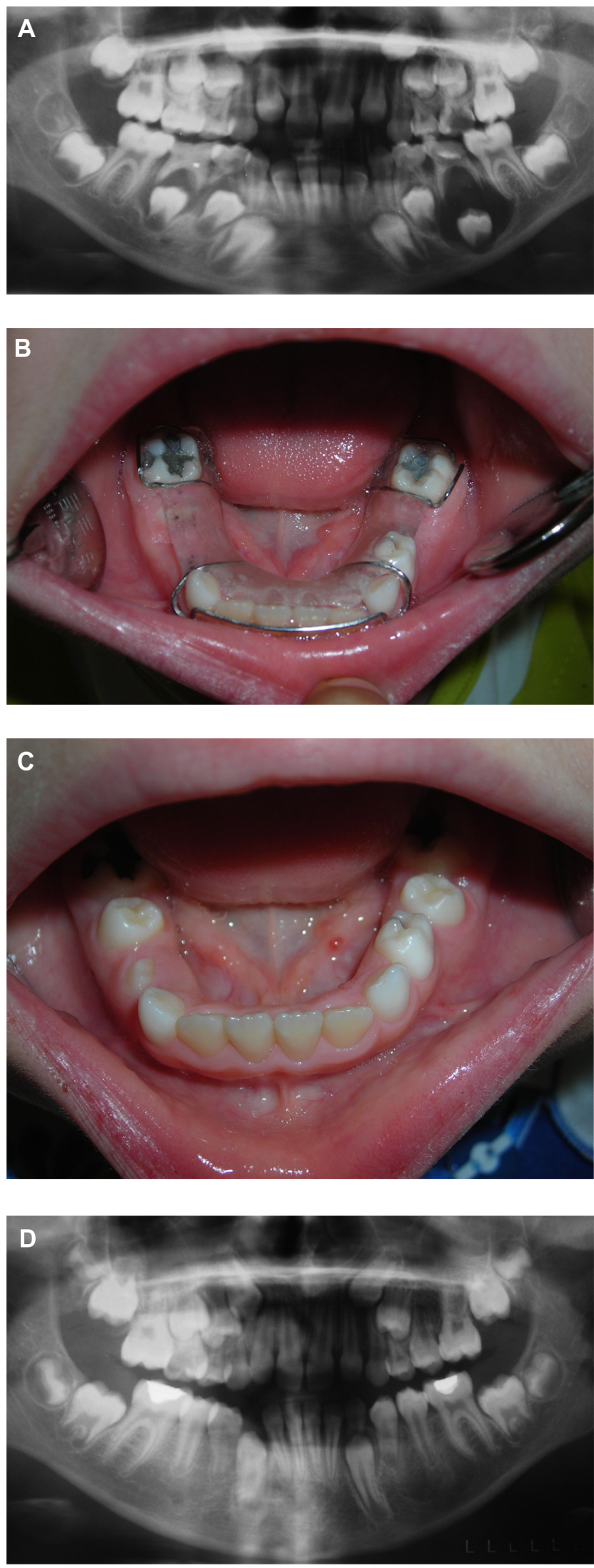

Figure I A) Radiological appearance before treatment of case I.B) Clinical appearance during healing of case I with modified decompression plaque. C) Clinical appearance during healing after eruption of second premolars. D) Radiological appearance after treatment of case $\mathrm{I}$.
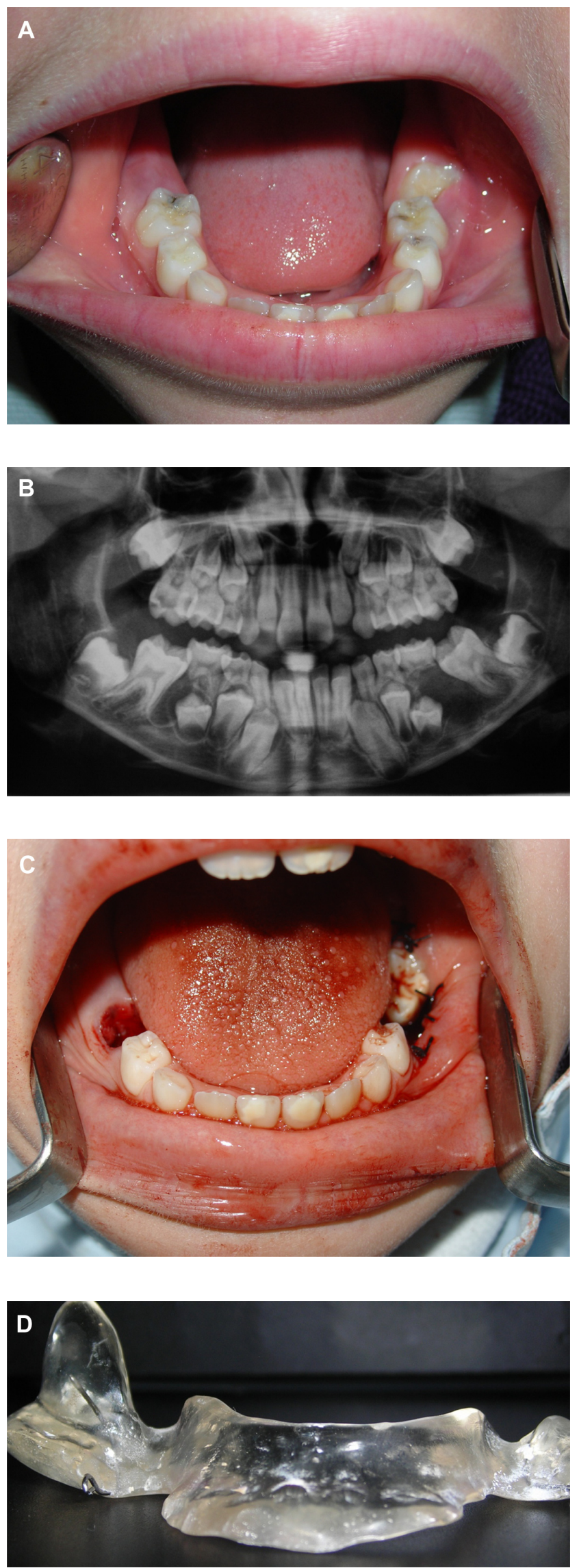

Figure 2 (Continued) 

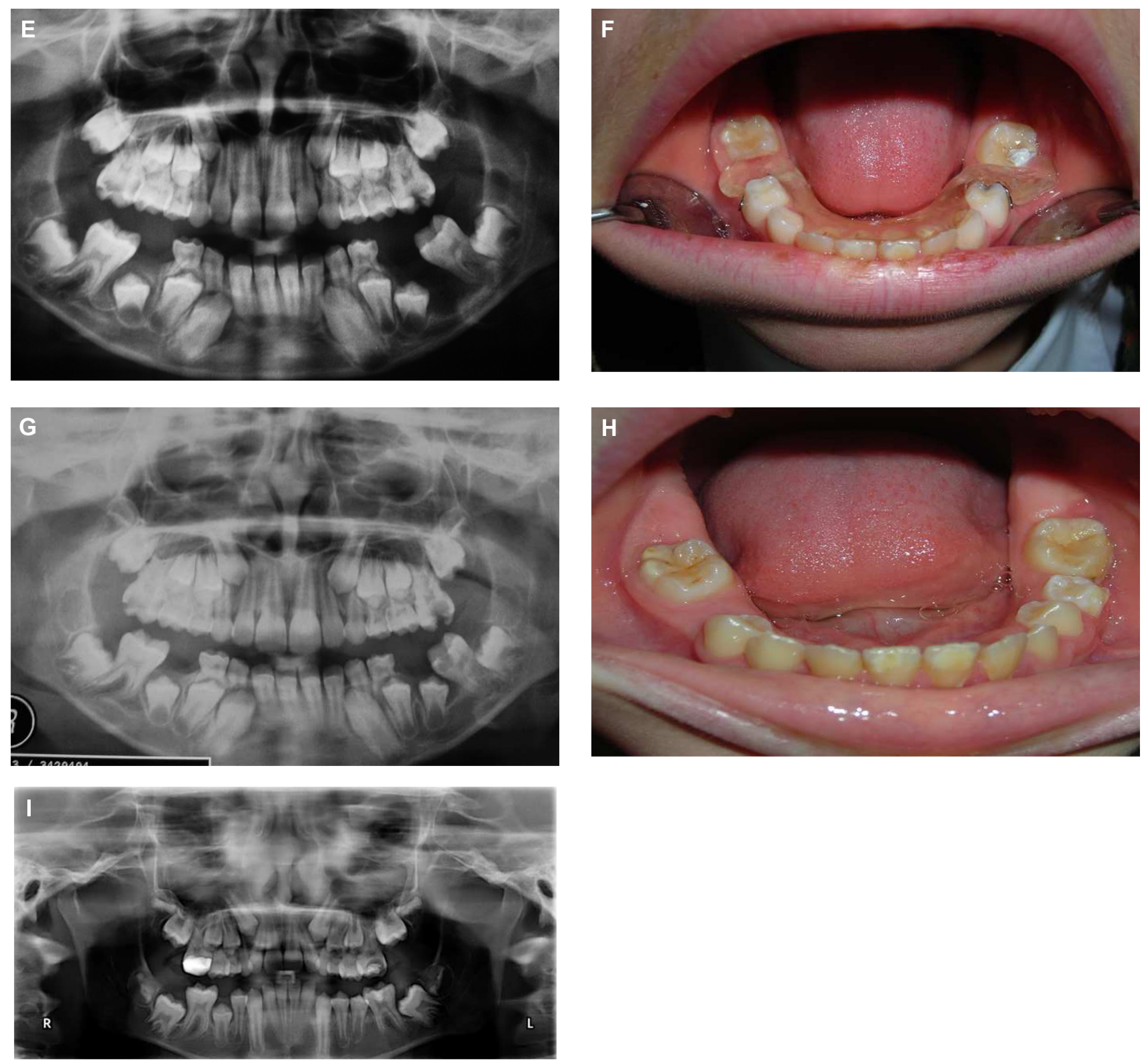

Figure 2 A) Clinical appearance before treatment of case 2. B) Radiological appearance before treatment of case 2. C) Clinical appearance after marsupialization of case 2. D) Modified decompression plaque. E) Radiological appearance after surgery of case 2. F) Clinical appearance during healing of case 2 with modified decompression plaque. G) Radiological appearance during healing of case 2. H) Clinical appearance after treatment of case 2. I) Radiological appearance after treatment of case 2.

The histopathologic examination of the lesions confirmed the diagnostic hypothesis of a dentigerous cyst. Examination of the surgical specimen obtained from the lesion revealed a cystic lesion lined by nonkeratinized squamous epithelium. No dysplastic changes were observed (Figure 4).

Eruptive movement of the permanent teeth was observed as well as new bone neoformation in the operation region after 3 to 4 months of follow-up.

The patients showed no evidence of local recurrence or distant spread either clinically or radiographically after 3 to 10 years of follow-up.

\section{Discussion}

Dentigerous cysts are very common developmental cysts which generally involve impacted, unerupted permanent teeth, supernumerary teeth, odontomas, and, rarely, decidious teeth They usually occur singly and are located in the mandible. Single dentigerous cysts are the second most common odontogenic cysts after radicular cysts. These cysts usually present in the second or third decades of life and are rarely seen during childhood. Bilateral and multiple dentigerous cysts have been reported in patients with syndromes such as mucopolysaccharidosis, basal cell nevus syndrome, and cleidocranial dysplasia. 

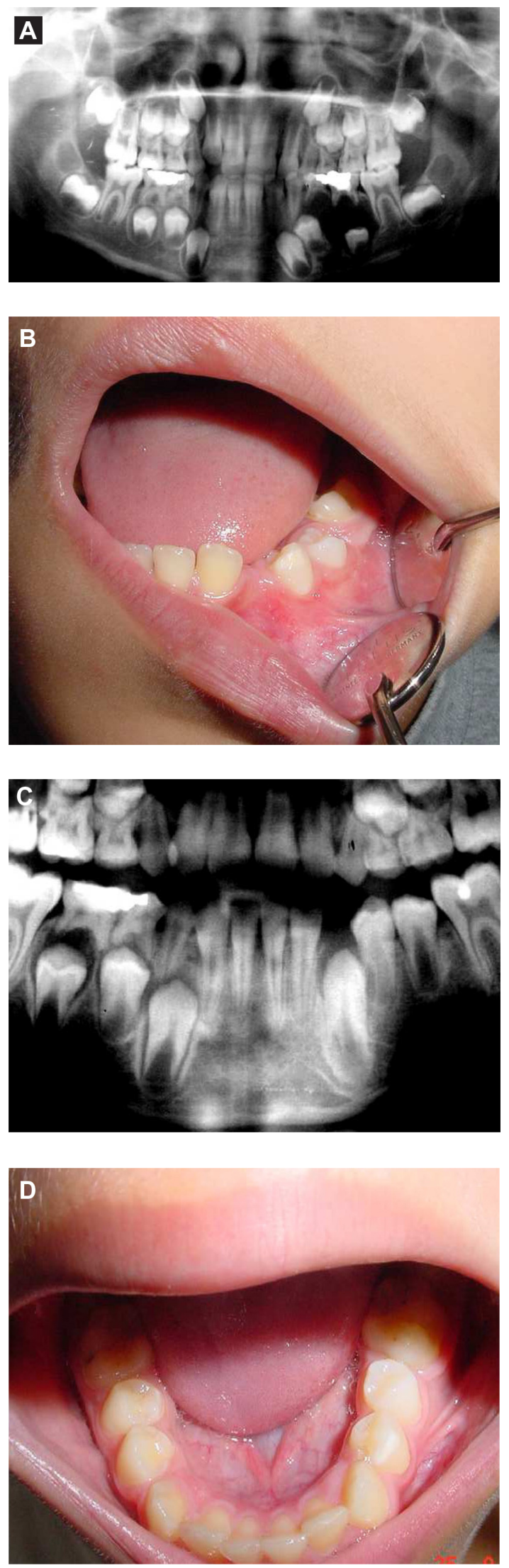

Figure 3 A) Radiological appearance before treatment of case 3. B) Clinical appearance after first marsupialization of case 3. C) New cystic lesion at the right lower premolars of case 3. D) Clinical appearance after treatment of case 3.

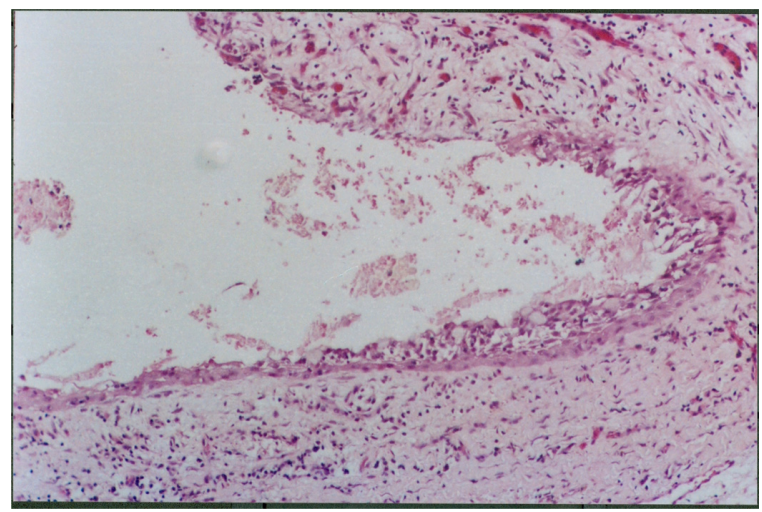

Figure 4 Histopathological appearance of the lesion (H\&E stain, $\times 44$ magnification).

Our patients were healthy children with no abnormal physical or laboratory findings suggesting any syndromes.

Patients with bilateral dentigerous cysts frequently present unerupted teeth or asymptomatic slow-growing swellings. ${ }^{4-8}$ They have also been reported in a patient with renal transplantation administered cyclosporine and amlodipine. ${ }^{9}$

On radiographic examination, dentigerous cysts appear as unilocular lucent cysts of varying size, with well-defined sclerotic borders, associated with the crown of an unerupted tooth. If a follicular space on radiography is more than $5 \mathrm{~mm}$, an odontogenic cyst can be suspected. Other odontogenic cysts such as hyperplastic dental follicle, radicular cysts, and odontogenic keratocysts, and odontogenic tumors such as ameloblastoma, Pindborg tumor, odontoma, odontogenic fibroma, and cemetomas may share the same radiologic features as dentigerous cysts. Of the lesions included in the differential diagnosis of dentigerous cysts, radicular cysts are the most common. Radicular cysts are odontogenic cysts that develop from a periapical granuloma in a carious tooth. Odontogenic keratocysts are often multilocular and most commonly located in the body or the ramus of the mandibula. Ameloblastoma is the most common radiolucent, benign odontogenic tumor which may be unilocular or multilocular. It may cause expansion and destruction of the maxilla and mandibula. Pindborg tumors are rare odontogenic tumors that are radiolucent with well-defined borders and associated calcified radiopaque foci. Odontomas and cementomas are lytic lesions most often accompanied by amorphous calcification. Odontogenic fibromyxoma usually has multiple radiolucent areas of varying size and bony septations, but unilocular lesions have also been described. ${ }^{11}$ Dentigerous cysts may not always look typical and radiographically can resemble other lesions. Histological diagnosis of these lesions is therefore critical. Surgical excision and pathologic analysis of the lesion is essential for the definitive diagnosis. 
According to a study by Freitas et al, ${ }^{5}$ only 17 cases of NSBDC have been reported in the literature from 1943 to 2005. A search of MEDLINE from 1967 to 2010, using the key words 'dentigerous cyst', 'bilateral', and 'multiple', was conducted and revealed no case series of NSBDC in growing patients. To our knowledge, 17 of 19 cases have been associated with mandibular molar teeth, $11^{4,10,13-16}$ of these being associated with third molar teeth and 8 associated with first and second molar teeth..$^{8,17-20}$ Only 2 of these were affecting the second premolars. The age range for reported cases varies widely, from 3 to 57 years. The mean age of the 19 cases was 23.57 years. Twelve of these occurred in patients under the age of 20 years and $7,10,12,14,16,21$ occured in patients older than 20 years. ${ }^{1,5,6,8,11,13,17-20}$ They usually present at under the age of 20 because of the tooth eruption chronology. ${ }^{5}$ The treatment of choice in 18 of the 19 reported NSBDC cases is enucleation of the cyst with removal of the tooth if necessary. There have been a few reports of spontaneous regression of a dentigerous cyst. ${ }^{12,22-25}$

The frequency of dentigerous cysts in studies that reported at least 50 dentigerous cysts varied from $9 \%$ to $38 \%{ }^{26}$ Prevalence of NSBDC in the Turkish population had not been reported before our case series reported here.

Treatment modalities range from enucleation to marsupialization, and are based on the premise that the pathological process can be controlled locally with minimal injury to the adjacent host structures. Smaller lesions are removed entirely to prevent damage to the involved permanent teeth, whereas larger lesions may be surgically drained and marsupialized to relieve the pressure within the cysts. Enucleation carries with it a risk that the developing tooth buds could be lost, which would necessitate reimplatation. The risk of injuring or losing the tooth buds was deemed too significant for removal of the cyst via enucleation. Marsupialization would allow for decompression of the cyst with preservation of the developing dentition. In addition, time would allow for continuous root development and some bone fill as the decompression evolved. In this study we prefered the marsupialization technique since it is a more conservative intervention for the treatment of large cysts, especially in pediatric dentistry, considering the frequent proximity of these lesions to the bud of developing permanent teeth, as observed here in the all presented cases. After marsupialization we used a removable space-maintaining appliance with a resin projection, which permitted decompression and prevented the entry of food into the cystic pouch. The technique prevented the formation of fibrous scars, which can impair eruption of the permanent tooth.
Cooperation of the parents was fundamental for treatment success. It is important to emphasize that the use of the marsupialization technique for treating cysts involving developing buds requires regular follow-up of the case until the permanent teeth erupt. As presented in our case 3, nonsyndromic unilateral dentigerous cysts are very common, but can be rarely seen in the form of bilateral metachronous dentigereous cysts. For this reason clinicians must be careful and observe the other healthy sides for new lesions.

The recurrence of dentigerous cysts is very rare. In the current study, no recurrence was seen in the long-term follow-up period (3-10 years).

In conclusion, marsupialization is an effective treatment with a low complication rate in growing patients. However, treatment planning, cooperation of the patients, and regular clinical follow-ups are necessary to ensure clinical success.

\section{Disclosure}

The authors report no conflicts of interest.

\section{References}

1. Sands TC. Multiple dentigerous cysts in a child. Oral Health. 1998;(88): 27-22.

2. Daley TD, Wysocki GP. The small dentigerous cyst: a diagnostic dilemma. Oral Surg Oral Med Oral Pathol Oral Radiol Endod. 1995;(79):77-81.

3. Gorlin RJ. Cysts of the jaws, oral floor and neck. In: Gorlin RJ, Goodman HW, editors. Thoma's Oral Pathology. Vol. 1. 6th ed. St. Louis: Mosby; 1970.

4. Ko KS, Dover DG, Jordan RC. Bilateral dentigerous cysts: report of an unusual case and review of the literature. J Can Dent Assoc. 1999;65(1): 49-51.

5. Freitas DQ, Tempest LM, Sicoli E, Lopes-Neto FC. Bilateral dentigerous cysts: review of the literature and report of an unusual case. Dentomaxillofac Radiol. 2006;35(6):464-468.

6. Batra P, Roychoudhury A, Balakrishan P, Parkash H. Bilateral dentigerous cyst associated with polymorphism in chromosome 1qh+. J Clin Pediatr Dent. 2004;28(2):177-181.

7. Roberts MW, Barton NW, Constantopoulos G, Butler DP, Donahue AH. Occurrence of multiple dentigerous cysts in a patient with the Maroteaux-Lamy syndrome (mucopolysaccharidosis, type VI). Oral Surg Oral Med Oral Pathol. 1984;58(2):169-175.

8. Trimble LD, West RA, Mc Neill RW. Cleidocranial dysplasia: comprehensive treatment of the dentofacial abnormalities. J Am Dent Assoc. 1982;105(4):661-666.

9. De Biase A, Ottolenghi L, Polimeni A, Benvenuto A, Lubrano R, Magliocca FM. Bilateral mandibular cysts associated with cyclosporine use: a case report. Pediatr Nephrol. 2001;16(12):993-995.

10. Burton DJ, Scheffer RB. Serratia infection in a patient with bilateral subcondylar impacted third molars and associated dentigerous cysts: report of case. J Oral Surg. 1980;38(2):135-138.

11. Ustuner E, Fitoz S, Atasoy C, Erden I, Akyar S. Bilateral maxillary dentigerous cysts: a case report. Oral Surg Oral Med Oral Pathol Oral Radiol Endod. 2003;(95):632-635.

12. Shah N, Thuau H, Beale I. Spontaneous regression of bilateral dentigerous cysts associated with impacted mandibular third molars. Br Dent J. 2002;192(2):75-76. 
13. Myers PB. Bilateral dentigerous cysts of the mandible. Br Dent $J$. 1943;74:67-68,

14. Banderas JA, Gonzalez M, Ramirez F, Arroyo A. Bilateral mucous cell containing dentigerous cysts of mandibular third molars: report of an unusual case. Arch Med Res. 1996;(27):327-329.

15. Crinzi RA. Bilateral dentigerous cysts of the mandible. Oral Surg Oral Med Oral Pathol. 1982;54(3):367.

16. Callaghan JH. Bilateral impaction of lower third molars in association with bilateral dentigerous cyst formation. A case report. Glasg Dent J. 1973;(4):36-38.

17. O'Neil DW, Mosby EL, Lowe JW. Bilateral mandibular dentigerous cysts in a five-year-old child: report of a case. ASDC J Dent Child. 1989;56(5):382-384.

18. Eidinger GB. Bilateral dentigerous cysts in the child patient. Report of a case and review of the literature. Univ Tor Dent J. 1989;(2):20-23.

19. Swerdloff M, Alexander SA, Ceen RF, Ferguson FS. Bilateral mandibular dentigerous cysts in a seven-year-old child. J Pedod. 1980;(5): 77-84.

20. Stanback JS. The management of bilateral cysts of the mandible Oral Surg Oral Med Oral Pathol. 1970;(30):587-591.

21. Henefer EP. Bilateral dentigerous cysts of the maxilla. Report of a case. Oral Surg Oral Med Oral Pathol. 1964;(17):296-298.
22. Bodner L, Woldenberg Y, Bar-Ziv J. Radiographic features of large cysts lesions of the jaws in children. Pediatr Radiol. 2003;33(1): 3-6.

23. Delbem AC, Cunha RF, Vieira AE, Pugliesi DM. Conservative treatment of radicular cyst in a 5-year-old child: a case report. Int J Paediatr Dent. 2003;13(6):447-450.

24. Adams AM, Walton AG. Case Report. Spontaneous regression of a radiolucency associated with an ectopic third molar. Dentomaxillofac Radiol. 1996;(25):162-164.

25. Freedman GL. A disappearing dentigerous cyst: report of a case. J Oral Maxillofac Surg. 1988;(46):885-886.

26. Zhang LL, Yang R, Zhang L, Li W, MacDonald-Jankowski D, Poh CF. Dentigerous cyst: a retrospective clinicopathological analysis of 2082 dentigerous cysts in British Columbia, Canada. Int J Oral Maxillofac Surg. 2010;39(9):878-882.

27. McDonnell DG. Bilateral dentigerous cysts. A case history. J Ir Dent Assoc. 1988;34(2):63.

28. Yamalık K, Bozkaya S, Erkmen E, Baris E. Nonsyndromic bilateral mandibular dentigerous cysts: report of a rare case. Turk Clin J Dental Sci. 2007;13(3):129-134.
Clinical, Cosmetic and Investigational Dentistry

\section{Publish your work in this journal}

Clinical, Cosmetic and Investigational Dentistry is an international, peer-reviewed, open access, online journal focusing on the latest clinical and experimental research in dentistry with specific emphasis on cosmetic interventions. Innovative developments in dental materials, techniques and devices that improve outcomes and patient satisfac-

\section{Dovepress}

tion and preference will be highlighted. The manuscript management system is completely online and includes a very quick and fair peerreview system, which is all easy to use. Visit http://www.dovepress. com/testimonials.php to read real quotes from published authors.

Submit your manuscript here: http://www.dovepress.com/clinical-cosmetic-and-investigational-dentistry-journal 